\title{
Pharmacokinetic Analysis of Four Bioactive Iridoid and Secoiridoid Glycoside Components of Radix Gentianae Macrophyllae and Their Synergistic Excretion by HPLC-DAD Combined with Second-Order
} \section{Calibration}

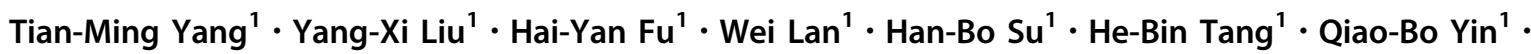 \\ He-Dong $\mathrm{Li}^{1} \cdot \mathrm{Li}^{-P i n g} \mathrm{Wang}^{1} \cdot \mathrm{Hai}-$ Long $\mathrm{Wu}^{2}$
}

Received: 31 October 2017 / Accepted: 10 November 2017 / Published online: 25 November 2017

(c) The Author(s) 2017. This article is an open access publication

\begin{abstract}
An HPLC-DAD method combined with second-order calibration based on the alternating trilinear decomposition (ATLD) algorithm with the aid of region selection was developed to simultaneously and quantitatively characterize the synergistic relationships and cumulative excretion of the four bioactive ingredients of Radix Gentianae Macrophyllae in vivo. Although the analytes spectra substantially overlapped with that of the biological matrix, the overlapping profiles between analytes and co-eluting interferences can be successfully separated and accurately quantified by the ATLD method on the basis of the strength of region selection. The proposed approach not only determined the content change but also revealed the synergistic relationships and the cumulative excretion in vivo of the four ingredients in urine and feces samples collected at different excretion time intervals. In addition, several statistical parameters were employed to evaluate the accuracy and precision of the method. Quantitative results were confirmed by HPLC-mass spectrometry. Satisfactory results indicated that the proposed approach can be utilized to investigate the pharmacokinetics of Radix Gentianae Macrophyllae excretion in vivo.
\end{abstract}

Hai-Yan $\mathrm{Fu}$

fuhaiyan@mail.scuec.edu.cn

$\triangle$ Hai-Long Wu

hlwu@hnu.edu.cn

1 The Modernization Engineering Technology Research Center of Ethnic Minority Medicine of Hubei Province, School of Pharmaceutical Sciences, South-Central University for Nationalities, Wuhan 430074, China

2 State Key Laboratory of Chemo/Biosensing and Chemometrics, College of Chemistry and Chemical Engineering, Hunan University, Changsha 410082, China 


\section{Graphical Abstract}
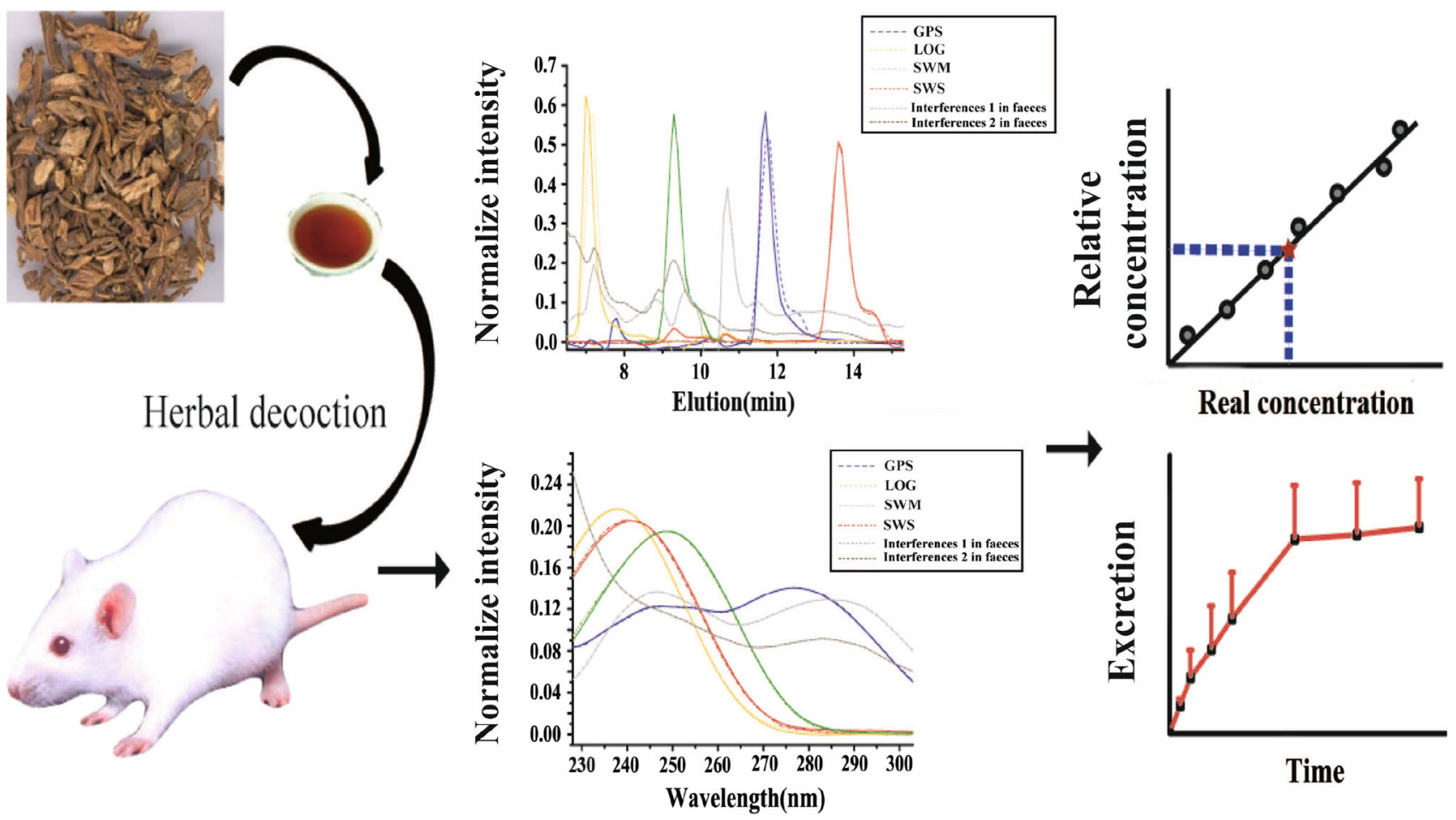

Keywords Radix Gentianae Macrophyllae · HPLC-DAD · Second-order calibration · Pharmacokinetic analysis

\section{Introduction}

Radix Gentianae Macrophyllae belongs to the Gentiana genus of Gentianaceae and is widely used as a remedy in traditional Chinese medicine (TCM) for more than 2000 years [1]. The dominant bioactive constituents in Radix Gentianae Macrophyllae are iridoid and secoiridoid glycosides, including gentiopicroside (GPS), loganic acid (LOG), swertiamarin (SWM), and sweroside (SWS), which exhibit analgesic, anti-inflammatory, antipyretic, antirheumatic, diuretic, febrifuge, and hypoglycemic pharmacological effects for treating hypotension, rheumatism, pains, fever, and allergic inflammations [2-6].

Unlike those of chemical drugs, the therapeutic effects of TCM are based on the synergistic effect of their bioactive compounds [7]. The determination of several components can not sufficiently represent the effects of TCM [8], whereas multi-component analysis helps reveal the effect of coordination among the TCM components
$[9,10]$. Thus, simultaneous quantification of bioactive ingredients in a complex physiological matrix is crucial.

Pharmacokinetics describes how the body affects a specific drug after administration through absorption and distribution, the chemical changes of the substance in the body, and the excretion effects and routes of metabolites in the drug [11]. Pharmacokinetic study on multiple components is a difficult field in TCM research because of the complicated and microscale nature of the chemical components of TCM.

Based on the available literature, several analytical methods, such as HPLC-UV [12, 13], UFLC-MS/MS [14], and LC/MS/MS [15], are available for quantifying bioactive ingredients derived from Radix Gentianae Macrophyllae in a biological matrix. Chromatographic analysis is an effective strategy to directly determine drugs. However, baseline drift and overlapping of peaks between matrix constituents and compounds of interest often occur in the chromatographic analysis of complex samples. For 
eliminating the influence of interfering compounds on analytes of interest, complex gradient elution is employed to isolate analytes. Several trivial sample pretreatments and instrumental parameters require optimization, entailing considerable energy, time, and cost.

Second-order calibration is widely used in numerous scientific areas, such as food quality and safety [16-24], cosmetic research [25, 26], environmental monitoring [27-30], biochemical assay [31-37], and routine analysis [38-40]. The strategy is a good solution to the previously mentioned problems because the concentrations of individual components can be accurately obtained even in the presence of uncalibrated interferences, that is, "secondorder advantage." Pharmacokinetic research on TCM is always performed using chromatographic technique, which offers advantages of powerful separation and analysis capabilities. However, an extremely complex gradient for sample separation and specific preprocessing procedures to optimize an internal standard is difficult to develop [41-44]. To the best of our knowledge, HPLC with a diode array detector (DAD) coupled with second-order calibration based on alternating trilinear decomposition (ATLD) has yet to be reported in drug excretion studies. Simultaneous determination of TCM bioactive substances in urine and feces samples after oral administration is challenging because of complex chemical components and trace amounts of bioactive ingredients. Therefore, researchers always use complex sample pretreatment, which require time and material and financial resources. By contrast, this practical problem can be potentially resolved through the development of chemometrics. The detection of the four bioactive components (GPS, LOG, SWM, and SWS) in Radix Gentianae Macrophyllae in urine and feces samples is influenced by unknown interferences. Furthermore, with the aid of second-order calibration, which maximizes the collected information in multi-way data arrays, the separation capability of routine chromatographic-based techniques can be enhanced by employing "mathematical separation" to partially substitute for "physical and chemical separation" $[45,46]$.

In the present work, a new analytical strategy was developed by employing HPLC-DAD coupled with second-order calibration based on the ATLD algorithm to simultaneously and quantitatively characterize the synergistic relationships and cumulative excretion of the four bioactive ingredients of Radix Gentianae Macrophyllae in vivo. Root-mean-square error of prediction (RMSEP), $t$ test, figures of merit (FOMs), including sensitivity (SEN), selectivity (SEL), limit of detection (LOD), and limit of quantification (LOQ), and reproducibility of inter-day analysis, were used to statistically validate the approach. In addition, HPLC-MS was used to evaluate the performance of the proposed approach. All results were satisfactory, indicating that the proposed strategy was simple, accurate, reliable, and time saving. The proposed strategy offers several advantages compared with other published methods: first, the combination of chemometric method with HPLC-DAD is originally applied to comprehensively quantify the four bioactive ingredients in most biological matrix systems. Second, the introduction of second-order calibration enables the separation of analytes in complex matrices in the same isocratic mode and without tedious pretreatment, thus simplifying the analysis procedure. Finally, widely used TCM, such as Radix Gentianae Macrophyllae, can be simultaneously analyzed under the same isocratic chromatographic condition. This approach provides a new foundation in clinical and toxicological monitoring, as well as routine pharmaceutical quality control.

\section{Theory}

\subsection{Trilinear Model for Second-Order Calibration}

In the case of HPLC-DAD analysis, a three-way data array $\mathbf{X}$, with dimensions of $I \times J \times K(I$ is the number of elution time scan point, $J$ is the number of selected UV spectrum channels, and $K$ is the number of samples including calibration and prediction samples) can be produced by stacking a series of HPLC-DAD data obtained for each of the $K$ samples. The trilinear component model is expressed in the following form:

$$
\begin{aligned}
x_{i j k}= & \sum_{n=1}^{N} a_{i n} b_{j n} c_{k n} \\
& +e_{i j k}(i=1,2, \ldots, I ; j=1,2, \ldots, J ; k=1,2, \ldots, K)
\end{aligned}
$$

where $N$ denotes the total number of detectable components of interest and the background as well as unknown interferences. $x_{i j k}$ represents the response intensity of sample $\mathrm{k}$ at elution time $\mathrm{i}$ and UV spectrum channel j. $c_{k n}$ is the element $(k, n)$ of an $K \times N$ matrix $\mathbf{C}$ with relative concentrations of the $N$ species in $K$ samples. $a_{i n}$ is the element $(i, n)$ of an $I \times N$ matrix $\mathbf{A}$ with elution profiles of the $N$ species. $b_{j n}$ is the element $(j, n)$ of an $J \times N$ matrix B with spectral profiles of the $N$ species, and $e_{i j k}$ is the element of the three-way residual array $\mathbf{E}(I \times J \times K)$.

\subsection{ATLD Algorithm}

The ATLD algorithm was developed by utilizing the alternating least-squares principle to solve the trilinear model proposed by $\mathrm{Wu}$ et al. [47]. Moore-Penrose generalized the inverse based on singular value decomposition 
and alternating iterative strategy to improve the performance of trilinear decomposition; the loss function reaches a minimum because of developed insensitivity to excessive component numbers, thus resulting in improved convergence. Moreover, with an appropriate signal-to-noise ratio, ATLD yields reasonable results even with high data collinearity. ATLD alternately minimizes the objective functions (2), (3), and (4) to update the qualitative profiles (A and $\mathrm{B}$ ) and the relative concentrations $(\mathrm{C})$ of individual components:

$$
\begin{aligned}
& \sigma_{1}(\mathbf{C})=\sum_{k=1}^{K}\left\|X_{. . k}-\mathbf{A} \operatorname{diag}\left(\boldsymbol{c}_{(k)}\right) \mathbf{B}^{T}\right\|_{F}^{2} \\
& \sigma_{2}(\mathbf{A})=\sum_{i=1}^{I}\left\|X_{i . .}-\mathbf{B} \operatorname{diag}\left(\boldsymbol{a}_{(i)}\right) \mathbf{C}^{T}\right\|_{F}^{2} \\
& \sigma_{3}(\mathbf{B})=\sum_{j=1}^{J}\left\|X_{. j .}-\mathbf{C} \operatorname{diag}\left(\boldsymbol{b}_{(j)}\right) \mathbf{A}^{T}\right\|_{F}^{2}
\end{aligned}
$$

\subsection{Figures of Merit}

FOMs, including SEN, SEL, LOD, and LOQ, are frequently used to optimize analytical methodology and verify the accuracy of the predicted results. In second-order calibration, FOM evaluation is closely related to the calculation of the net analyte signal (NAS), which is defined as the part of the signal that relates uniquely to the NAS. SEN is estimated as the NAS at unit concentration, which is defined as the slope of the calibration curve in the context of univariate calibration. SEL is the ratio between SEN and the total signal. The LOD of a method is the lowest quantity of a substance that can be distinguished from its absence (blank value) within a stated confidence limit, and the LOQ of a method is the limit at which the difference between two different values can be determined. The formulas of FOMs are as follows:

$$
\begin{aligned}
& \mathrm{SEN}=\lambda\left\{\left[\left(\mathbf{A}^{T} \mathbf{A}\right)^{-1}\right] \times\left[\left(\mathbf{B}^{T} \mathbf{B}\right)^{-1}\right]\right\}_{n n}^{-1 / 2} \\
& \mathrm{SEL}=\left\{\left[\left(\mathbf{A}^{T} \mathbf{A}\right)^{-1}\right] \times\left[\left(\mathbf{B}^{T} \mathbf{B}\right)^{-1 / 2}\right]\right\}_{n n}^{-1 / 2} \\
& \mathrm{LOD}=3.3 s(0) \\
& \mathrm{LOQ}=10 s(0)
\end{aligned}
$$

where $n n$ means the $(n, n)$ diagonal element of the matrix $\left[\left(\mathbf{A}^{T} \mathbf{A}\right)^{-1} \times\left(\mathbf{B}^{T} \mathbf{B}\right)^{-1}\right], \lambda$ is the total signal for component $n$ at unit concentration, and the symbol $\times$ indicates the Hadamard product. $s(0)$ is the standard deviation in the predicted concentration for three different background blank samples, in the algorithms.
RMSE can be calculated using the formula as RMSEP $=\left[\frac{I}{I-1} \sum_{i=1}^{I}\left(C_{a c t}-C_{\text {pred }}\right)^{2}\right]^{1 / 2}$, where $I$ is the number of prediction samples, $C_{a c t}$ and $C_{\text {pred }}$ are the actual and predicted concentrations of the analytes, respectively.

\section{Materials and Methods}

\subsection{Chemicals and Reagents}

HPLC-grade methanol was purchased from Tedia (USA). Acetic acid (analytical grade) was obtained from Sinopharm Chemical Reagent Co., Ltd. (Shanghai, China). Standards of gentiopicroside, loganic acid, swertiamarin and sweroside were provided by the National Institutes for Food and Drug Control (China). Healthy adult healthy male Sprague-Dawley (SD) rats were purchased from Hubei Research Center of Experimental Animals (SCXK(E)2008-0005).

\subsection{Instrument}

HPLC was performed using an UltiMate 3000 liquid chromatographic system (Thermo-Dionex Corporation, USA) equipped with a DAD, an auto sampler, and a column compartment. Separation was carried out in a $\mathrm{C}_{18}$ column $(250 \times 4.6 \mathrm{~mm}, 5.0 \mathrm{~mm}$ particle size, Thermo Scientific Syncronis, USA). A centrifuge (Star Scientific Instrument Co., Ltd., China) and ultrasonic instrument (China) were used during sample preparation.

Mass spectrometry was conducted on an Agilent 6520 Q-TOF tandem mass spectrometer equipped with an electrospray ionization (ESI) source (Agilent Corp., USA).

\subsection{Sample Preparation}

\subsubsection{Preparation of the Calibration and Validation Samples}

Stock standard solutions of GPS, LOG, SWM, and SWS were prepared separately in methanol at concentrations of $1.56,2.08,1.68$, and $1.20 \mathrm{mg} \mathrm{mL}^{-1}$. The first fourteenth Samples (C1-C14) were built as a calibration set. In addition, 10 samples (V1-V10) as a test set were prepared with the analytes concentrations within its corresponding calibration range, which were used to validate the chemometric model. The concentrations of four analytes in both calibration and validation samples were listed in Table 1. 
Table 1 Concentration of each analyte in calibration and validation samples

\begin{tabular}{|c|c|c|c|c|}
\hline \multirow[t]{2}{*}{ Samples } & \multicolumn{4}{|c|}{ Spiked value $\left(\mu \mathrm{g} \mathrm{mL}^{-1}\right)$} \\
\hline & GPS & LOG & SWM & SWS \\
\hline \multicolumn{5}{|c|}{ Calibration samples } \\
\hline $\mathrm{C} 1$ & 34.63 & 0.00 & 0.00 & 0.00 \\
\hline $\mathrm{C} 2$ & 0.00 & 45.76 & 0.00 & 0.00 \\
\hline $\mathrm{C} 3$ & 0.00 & 0.00 & 44.35 & 0.00 \\
\hline $\mathrm{C} 4$ & 0.00 & 0.00 & 0.00 & 42.00 \\
\hline C5 & 4.99 & 41.60 & 6.05 & 38.16 \\
\hline C6 & 8.11 & 37.44 & 10.08 & 34.32 \\
\hline $\mathrm{C} 7$ & 11.23 & 33.28 & 14.11 & 30.48 \\
\hline $\mathrm{C} 8$ & 14.35 & 29.12 & 18.14 & 26.64 \\
\hline C9 & 17.47 & 24.96 & 22.18 & 22.80 \\
\hline $\mathrm{C} 10$ & 20.59 & 20.80 & 26.21 & 18.96 \\
\hline $\mathrm{C} 11$ & 23.71 & 16.64 & 30.24 & 15.12 \\
\hline $\mathrm{C} 12$ & 26.83 & 12.48 & 34.27 & 11.28 \\
\hline $\mathrm{C} 13$ & 29.95 & 8.32 & 38.30 & 7.44 \\
\hline $\mathrm{C} 14$ & 33.07 & 4.16 & 42.34 & 3.60 \\
\hline \multicolumn{5}{|c|}{ Validation samples } \\
\hline V1 & 3.43 & 43.68 & 4.03 & 40.08 \\
\hline $\mathrm{V} 2$ & 6.55 & 39.52 & 8.06 & 36.24 \\
\hline V3 & 9.67 & 35.36 & 12.1 & 32.4 \\
\hline V4 & 12.79 & 31.2 & 16.13 & 28.56 \\
\hline V5 & 15.91 & 27.04 & 20.16 & 24.72 \\
\hline V6 & 19.03 & 22.88 & 24.19 & 20.88 \\
\hline V7 & 22.15 & 18.72 & 28.22 & 17.04 \\
\hline V8 & 25.27 & 14.56 & 32.26 & 13.2 \\
\hline V9 & 28.39 & 10.4 & 36.29 & 9.36 \\
\hline V10 & 31.51 & 6.24 & 40.32 & 5.52 \\
\hline
\end{tabular}

\subsubsection{Pretreatment of Rat Urine and Feces Samples}

Protein precipitation was applied to extract four bioactive ingredients from rat urine and feces samples. Five healthy male SD rats were housed in stainless-steel metabolic cages equipped with urine-feces separators. Urine and feces samples were collected at different time intervals (namely, $0-2,2-4,4-8,8-12,12-24,24-36$, and $36-48$ h) postdosage. Feces samples collected from different time points were dried using a heated oven at $40{ }^{\circ} \mathrm{C}$ and then pulverized. $5 \mathrm{~mL} \mathrm{~g}^{-1}$ physiological saline solution was added and homogenized with the pulverized feces, and $100 \mu \mathrm{L}$ feces supernatant from homogenate was blended with $400 \mu \mathrm{L}$ of methanol. The mixture was vigorously vortexed for approximately $1 \mathrm{~min}$ and then centrifuged at $12000 \mathrm{rpm}$ for $15 \mathrm{~min}$ at $4{ }^{\circ} \mathrm{C}$. Then, $400 \mu \mathrm{L}$ of the supernatant was transferred to a new $1.5 \mathrm{~mL}$ centrifuge tube and completely evaporated under a gentle stream of nitrogen. Residues were dissolved in $100 \mu \mathrm{L}$ of the mobile phase, and $10 \mu \mathrm{L}$ of sample solutions was injected into the HPLC-DAD for analysis. Urine samples were treated in a similar manner; however, $500 \mu \mathrm{L}$ methanol was used in the protein precipitation stage, and $500 \mu \mathrm{L}$ supernatant was dried.

\subsubsection{Preparation of Quality Control Samples in Urine and Feces}

Three levels of high, middle, and low concentration were prepared as working solution by diluting the stock standard solutions with methanol. GPS, LOG, SWM, and SWS in working solutions with high concentration level were at $49.92,58.24,33.60$, and $24.00 \mu \mathrm{g} \mathrm{mL}^{-1}$, respectively. GPS, LOG, SWM, and SWS in working solutions with level of middle concentration were at 30.58, 36.40, 23.86, and $18.6 \mu \mathrm{g} \mathrm{mL}^{-1}$, respectively. GPS, LOG, SWM, and SWS in working solutions with low concentration were at $11.23,14.56,14.11$, and $13.2 \mu \mathrm{g} \mathrm{mL}^{-1}$, respectively. For urine quality control (QC) samples; high, middle and low concentration levels of working solution $(60 \mu \mathrm{L})$ were transferred separately into three $1.5 \mathrm{~mL}$ centrifuge tubes and dried with nitrogen, and then $300 \mu \mathrm{L}$ blank urine samples was added to each tube. Methanol $(1500 \mu \mathrm{L})$ was used for protein precipitation. The mixture was vigorously vortexed for approximately $1 \mathrm{~min}$ and then centrifuged at $12000 \mathrm{rpm}$ and $4{ }^{\circ} \mathrm{C}$ for $15 \mathrm{~min}$. Then, $1500 \mu \mathrm{L}$ of the supernatant was transferred to a new $1.5 \mathrm{~mL}$ centrifuge tube and evaporated to dryness under a gentle stream of nitrogen. Residues were dissolved in $300 \mu \mathrm{L}$ of mobile phase before analysis. Feces QC samples were treated in a similar manner, except $1200 \mu \mathrm{L}$ methanol was used in the protein precipitation stage, and $1200 \mu \mathrm{L}$ supernatant was dried. The concentrations of the four analytes in urine and feces QC samples were summarized in Table 2.

\subsubsection{Preparation of Radix Gentianae Macrophyllae Water Decoction}

One hundred grams of Radix Gentianae Macrophyllae was mixed with $1000 \mathrm{~mL}$ distilled water and heated to boiling for $30 \mathrm{~min}$. The residual part was added in $1000 \mathrm{~mL}$ distilled water and heated to boiling for $30 \mathrm{~min}$. This procedure was repeated twice. Eventually, $50 \mathrm{~mL}$ water extract was obtained at a concentration of $2 \mathrm{~g} \mathrm{~mL}^{-1}$ crude drug. The water extract was diluted separately to obtain concentrations of 1 and $1.5 \mathrm{~g} \mathrm{~mL}^{-1}$ crude drug for storage at $4{ }^{\circ} \mathrm{C}$.

\subsection{Excretion Study}

For urinary and fecal excretion study, 5 healthy SD male rats were housed in stainless-steel metabolic cages with free access to water and fasted for $12 \mathrm{~h}$ before the experiment. Urine and feces samples of each rat at $0 \mathrm{~h}$ (control) 
Table 2 Concentrations of four analytes in urine and feces QC samples

\begin{tabular}{|c|c|c|c|c|c|c|c|c|}
\hline \multirow[t]{2}{*}{ Analytes } & \multicolumn{2}{|c|}{ GPS $\left(\mu \mathrm{g} \mathrm{mL}^{-1}\right)$} & \multicolumn{2}{|c|}{$\operatorname{LOG}\left(\mu \mathrm{g} \mathrm{mL}^{-1}\right)$} & \multicolumn{2}{|c|}{$\mathrm{SWM}\left(\mu \mathrm{g} \mathrm{mL}^{-1}\right)$} & \multicolumn{2}{|c|}{ SWS $\left(\mu \mathrm{g} \mathrm{mL} L^{-1}\right)$} \\
\hline & Urine & Feces & Urine & Feces & Urine & Feces & Urine & Feces \\
\hline $\mathrm{H}$ & 8.32 & 7.99 & 9.71 & 9.32 & 5.60 & 5.38 & 4.00 & 3.84 \\
\hline M & 5.10 & 4.89 & 6.07 & 5.82 & 3.98 & 3.82 & 3.10 & 2.98 \\
\hline $\mathrm{L}$ & 1.87 & 1.80 & 2.43 & 2.33 & 2.35 & 2.26 & 2.20 & 2.11 \\
\hline
\end{tabular}

were collected before the experiment, and a Radix Gentianae Macrophyllae decoction at a single dose of $16 \mathrm{~g} \mathrm{~kg}^{-1}$ was administered as described above. Food was returned at approximately $4 \mathrm{~h}$ post-dosing, and then urine and feces were collected at $0-2,2-4,4-8,8-12,12-24$, 24-36, and 36-48 $\mathrm{h}$ post-dosing as prediction samples. Urine volume was recorded, and dried feces was weighed. Then, specimens were stored at $-20{ }^{\circ} \mathrm{C}$ until analysis.

\subsection{Establishment of Detection Conditions}

Liquid chromatography was performed on liquid chromatographic system (DIONEX Corporation, USA) equipped with DAD. Separation was carried out on a $\mathrm{C}_{18}$ column (Thermo Scientific Syncronis, $250 \times 4.6 \mathrm{~mm}, 5.0 \mathrm{~mm}$ particle size). The isocratic mobile phase consisted of methanol and water acidified with $0.1 \%$ acetic acid solution $(3: 7, \mathrm{v} / \mathrm{v})$ and was pumped at a flow rate of $1.0 \mathrm{~mL} \mathrm{~min}^{-1}$ with $10 \mu \mathrm{L}$ injection volume. Column temperature was set at $30{ }^{\circ} \mathrm{C}$. Photometric detection was performed in the range of 190-600 nm with a spectral interval of $1 \mathrm{~nm}$.

Mass spectra were detected on an Agilent 6520 Q-TOF tandem mass spectrometer equipped with an ESI source (Agilent Corp., USA). The LOG ESI source was set to negative ionization mode, whereas the ESI source of GPS, SWM, and SWS were set to positive ionization mode. The MS operating conditions were optimized as follows: scanning spectrum range from 100 to $800 \mathrm{~m} / \mathrm{z}$, nebulizer pressure of 30 psi $\left(\mathrm{N}_{2}\right)$, dry gas temperature of $300{ }^{\circ} \mathrm{C}$, spray voltage of $3500 \mathrm{~V}$, skimmer voltage of $125 \mathrm{~V}$, and nitrogen at $10 \mathrm{~L} \mathrm{~min}^{-1}$ as dry gas.

Three-way data produced by HPLC-DAD were imported to a microcomputer with a Windows Server 2008 operating system and analyzed in Matlab environment.

\section{Results and Discussion}

\subsection{Establishment and Validation of Calibration Models for Excretion Study}

Four bioactive ingredients were eluted within $16 \mathrm{~min}$ in isocratic mode, as shown in Fig. 1. The four analytes were separated successfully under current chromatographic separation condition.

The rat urine and feces samples were administered with alow-level Radix Gentianae Macrophyllae water decoction (16 $\left.\mathrm{g} \mathrm{kg}^{-1}\right)$ within $2-4 \mathrm{~h}$ to show the typical chromatographic plot in Fig. 2. Unfortunately, chromatographic profiles from four bioactive ingredients heavily overlapped with that of biological matrix interferences from urine and feces samples under the same chromatographic separation condition. Therefore, traditional HPLC analytical methods provide invalid quantitative results without careful extraction and separation procedures. Great effort may be necessary to optimize the chromatographic conditions of the separation for the problem, but a complicated chromatographic condition means more time and resources would be consumed. Alternatively, one can resort to the second-order calibration method based on ATLD algorithm, which allows the relative chromatographic, spectral, and concentration profiles of analytes to be extracted even in the presence of uncalibrated interferences.

Therefore, for excretion studies, prior to an estimate of the concentration of four bioactive ingredients in urine and feces, Validation samples (V1-V10) were utilized to validate whether the calibration model was reliable. In order to avoid the interference from irrelevant data and simplify the analytical process, total chromatographic data registered for each sample was segmented in two three-way data array for mathematical modeling, namely the first data array $(89 \times 76 \times 24)$ was constructed by an elution time range of $6.5-15.3 \mathrm{~min}(\Delta \mathrm{t}=0.1 \mathrm{~s})$ and a wavelength range of 225-300 $\mathrm{nm}(\Delta \lambda=1 \mathrm{~nm})$ for the analysis GPS, LOG and SWS, the second data array $(23 \times 49 \times 24)$ was constructed by selecting the elution time range of 8.4-10.6 $\min (\Delta \mathrm{t}=0.1 \mathrm{~s})$ and the wavelength range of $232-280 \mathrm{~nm}(\Delta \lambda=1 \mathrm{~nm})$ for the analysis of SWM. The quantitative results of concentrations of validation samples (V1-V10) were shown in Table 3.

The average recoveries of GPS, LOG, SWS, and SWM in 10 validation samples were $100.2 \pm 2.4,99.4 \pm 2.8$, $100.4 \pm 2.6$, and $100.7 \pm 1.7 \%$, and the calculated RMSEP values were 1.51, 2.30, 2.41 and $1.90 \mu \mathrm{g} \mathrm{mL}^{-1}$, respectively. The $t$-test was carried out to compare recoveries with the ideal value of $100 \%$ for all four analytes. $T<t_{0.025}^{9}$, suggesting no significant difference between the 

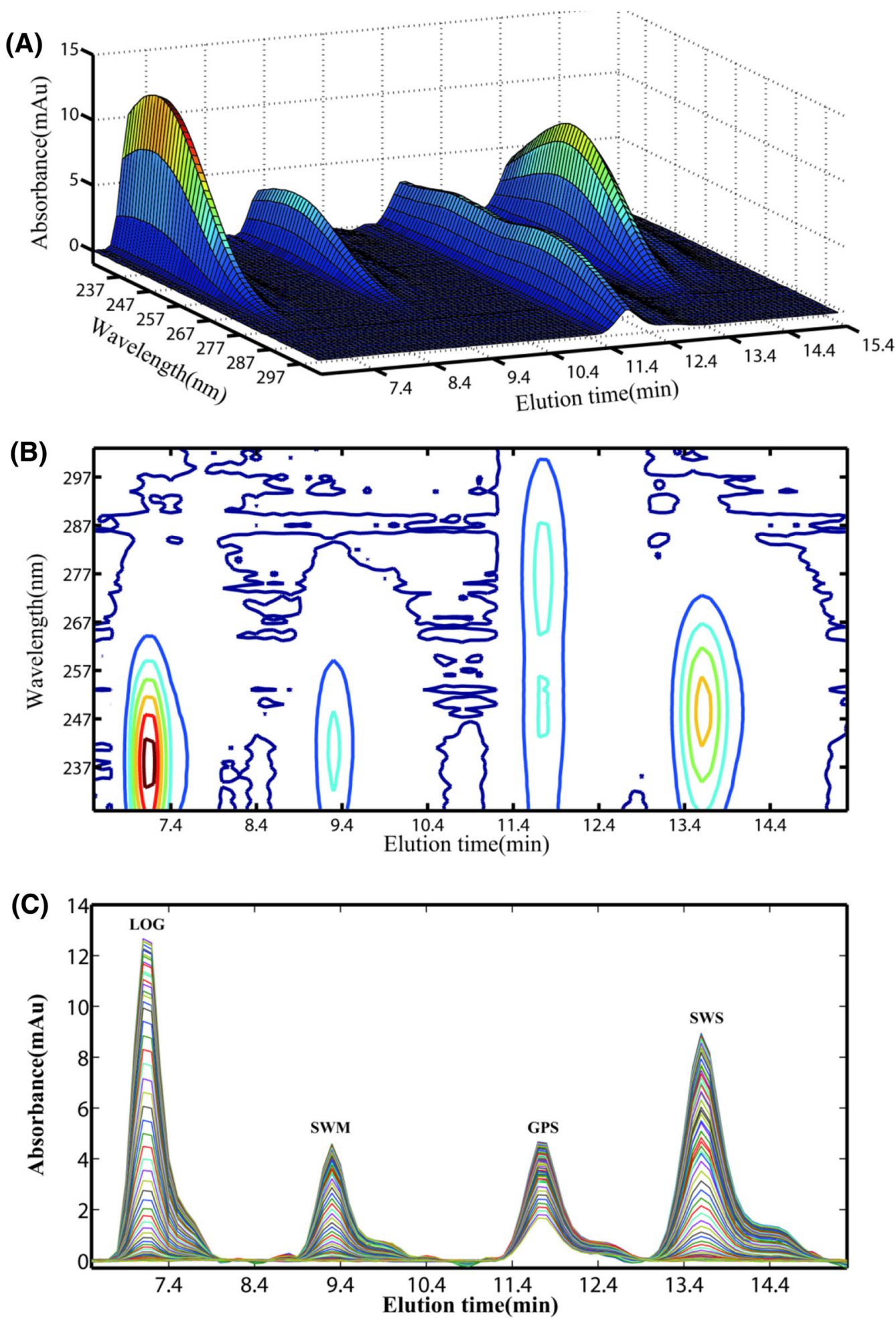

Fig. 1 a Three-dimensional plot of HPLC-DAD data for four analytes; $\mathbf{b}$ contour plot of HPLC-DAD data for four analytes; $\mathbf{c}$ chromatograms of four analytes at different wavelengths

results under the confidence level of $95 \%$. The results clearly indicate that ATLD are reliable for the simultaneous quantification of GPS, LOG, SWM, and SWS. In addition, the QC samples in urine and feces were adopted to investigate extraction recovery, precision, and stability of the established method. The QC samples were analyzed in triplicate in a day. This assay was repeated for 3 days. Satisfactory extraction capacities toward the four analytes 


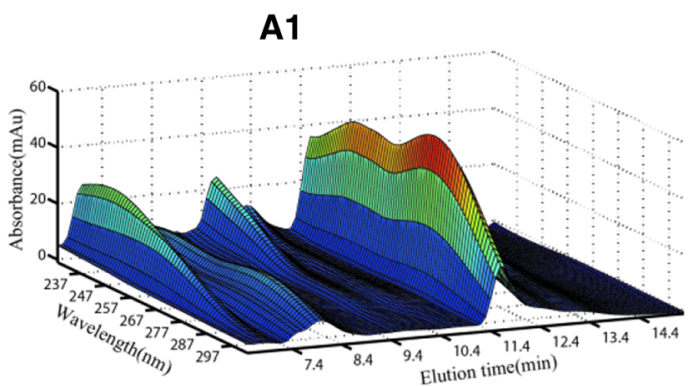

B1

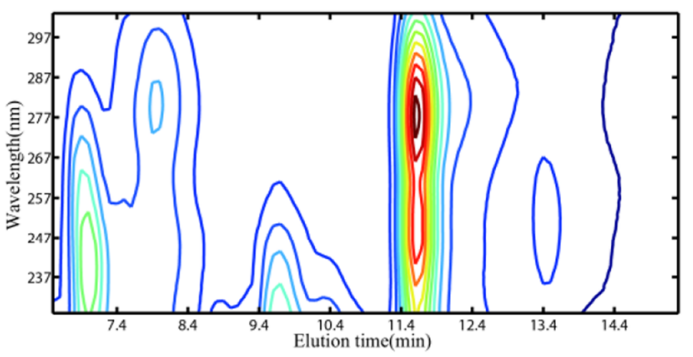

C1

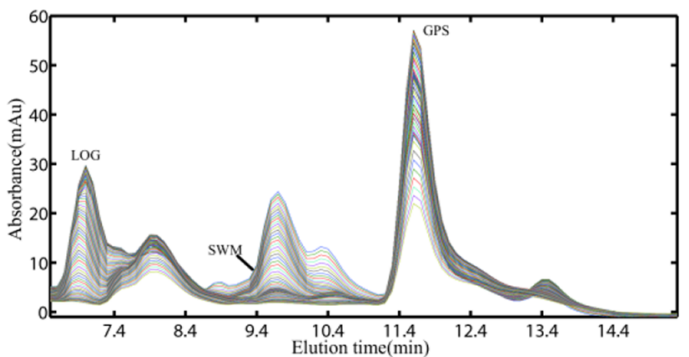

Fig. 2 Three-dimensional plot of a typical chromatogram of urine (a1) and feces samples (a2) from rat administered with low dosage of Radix Gentianae Macrophyllae water decoction $\left(16 \mathrm{~g} \mathrm{~kg}^{-1}\right)$ within

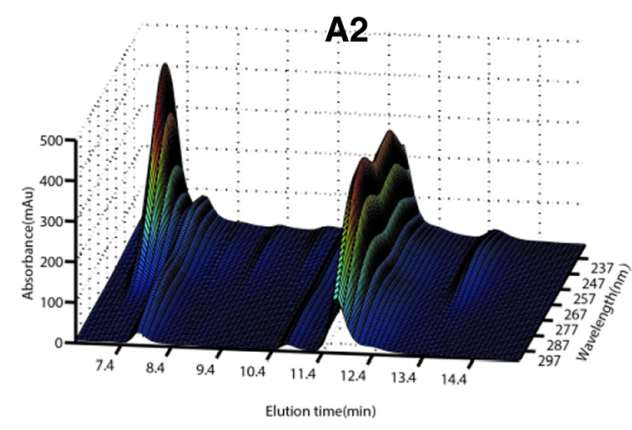

B2

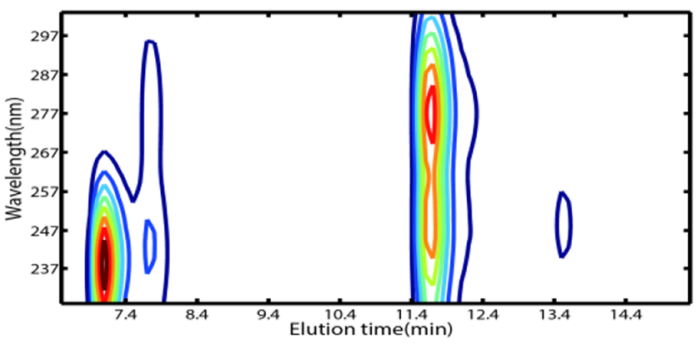

C2

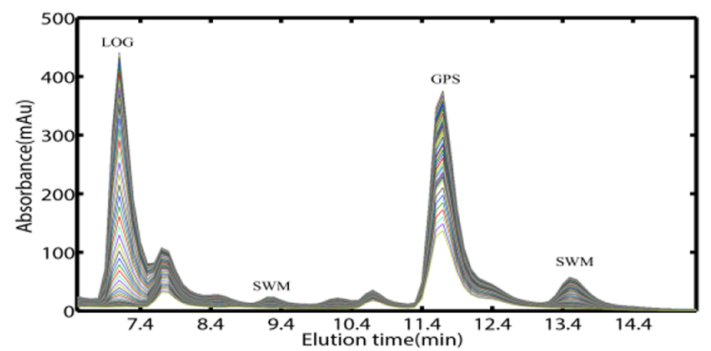

2-4 h; b1, b2 are contour plots corresponding to a1, a2, respectively. Chromatograms recorded at various wavelength channels for urine (c1) and feces samples (c2)

Table 3 Predicted concentrations of validation samples

\begin{tabular}{|c|c|c|c|c|}
\hline \multirow[t]{2}{*}{ Validation sample } & \multicolumn{4}{|c|}{ Predicted value $\left(\mu \mathrm{g} \mathrm{mL}^{-1}\right)$ [recovery $\left.(\%)\right]$} \\
\hline & GPS & LOG & SWM & SWS \\
\hline V1 & 3.27 [95.3] & $44.82[102.6]$ & $4.03[100.0]$ & $42.49[106.0]$ \\
\hline $\mathrm{V} 2$ & $6.47[98.8]$ & $39.86[100.9]$ & $7.94[98.5]$ & $36.69[101.2]$ \\
\hline V3 & $9.51[98.4]$ & $35.3[99.8]$ & $12.06[99.7]$ & $32.27[99.6]$ \\
\hline V4 & $12.83[100.3]$ & $30.78[98.7]$ & $16.15[100.1]$ & $28.49[99.8]$ \\
\hline V5 & $15.88[99.8]$ & $26.79[99.1]$ & $20.06[99.5]$ & $24.27[98.2]$ \\
\hline V6 & $19.89[104.5]$ & 23.49 [102.7] & $25.11[103.8]$ & $21.47[102.8]$ \\
\hline V7 & $22.40[101.1]]$ & $18.43[98.5]$ & $28.96[102.6]$ & $16.67[97.8]$ \\
\hline V8 & $25.78[102.0]$ & $14.39[98.8]$ & 32.82 [101.7] & $13.02[98.6]$ \\
\hline V9 & $28.48[100.3]$ & $10.44[100.4]$ & $36.15[99.6]$ & $9.17[98.0]$ \\
\hline V10 & $31.85[101.1]$ & $5.79[92.8]$ & $41[101.7]$ & $5.64[102.2]$ \\
\hline Average recovery $(\%)$ & $100.2 \pm 2.4$ & $99.4 \pm 2.8$ & $100.7 \pm 1.7$ & $100.4 \pm 2.6$ \\
\hline RMSEP & 1.51 & 2.30 & 1.90 & 2.41 \\
\hline$T$ ( $t$-test) & $0.21<\mathrm{t}_{0.025}^{9}$ & $0.66<\mathrm{t}_{0.025}^{9}$ & $1.39<\mathrm{t}_{0.025}^{9}$ & $0.52<\mathrm{t}_{0.025}^{9}$ \\
\hline
\end{tabular}


Table 4 Intra-day and inter-day accuracy and precision of four bioactive ingredients in rat urine and feces QC samples

\begin{tabular}{|c|c|c|c|c|c|c|c|}
\hline \multirow[t]{2}{*}{ Matrix } & \multirow[t]{2}{*}{ Analytes } & \multicolumn{2}{|c|}{ Concentration $\left(\mu \mathrm{g} \mathrm{mL}^{-1}\right)$} & \multicolumn{2}{|c|}{ Precision (RSD, \%) } & \multicolumn{2}{|c|}{ Accuracy (RE, \%) } \\
\hline & & Spiked & Measured (mean $\pm \mathrm{SD}$ ) & Intra-day & Inter-day & Intra-day & Inter-day \\
\hline \multirow[t]{12}{*}{ Urine } & \multirow[t]{3}{*}{ GPS } & 8.32 & $8.44 \pm 0.13$ & 1.5 & 6.3 & 1.4 & -2.5 \\
\hline & & 5.10 & $5.19 \pm 0.24$ & 4.7 & 4.6 & 1.8 & -1.2 \\
\hline & & 1.87 & $2.21 \pm 0.50$ & 14.9 & 14.4 & -8.1 & 6.6 \\
\hline & \multirow[t]{3}{*}{ LOG } & 9.71 & $10.9 \pm 0.07$ & 0.7 & 2.9 & 3.9 & 0.7 \\
\hline & & 6.07 & $6.84 \pm 0.17$ & 2.4 & 7.4 & 12.8 & -3.3 \\
\hline & & 2.43 & $1.77 \pm 0.13$ & 4.6 & 16.2 & 7.7 & 4.2 \\
\hline & \multirow[t]{3}{*}{ SWM } & 5.60 & $4.77 \pm 0.25$ & 5.2 & 6.7 & -14.9 & -6.5 \\
\hline & & 3.98 & $3.11 \pm 0.16$ & 5.0 & 3.1 & -15.1 & -6.9 \\
\hline & & 2.35 & $2.54 \pm 0.39$ & 15.5 & 9.5 & 7.9 & -7.8 \\
\hline & \multirow[t]{3}{*}{ SWS } & 4.00 & $3.86 \pm 0.84$ & 3.9 & 1.3 & -12.4 & 5.5 \\
\hline & & 3.10 & $3.28 \pm 0.04$ & 1.1 & 10.0 & 5.8 & 2.5 \\
\hline & & 2.20 & $2.49 \pm 0.15$ & 5.8 & 17.6 & 13.3 & -7.3 \\
\hline \multirow[t]{12}{*}{ Feces } & \multirow[t]{3}{*}{ GPS } & 7.99 & $8.04 \pm 0.39$ & 5.2 & 4.9 & 1.3 & 0.6 \\
\hline & & 4.89 & $4.80 \pm 0.12$ & 2.4 & 2.5 & -0.4 & -2.0 \\
\hline & & 1.80 & $1.70 \pm 0.04$ & 4.8 & 2.6 & 1.2 & -5.4 \\
\hline & \multirow[t]{3}{*}{ LOG } & 9.32 & $9.38 \pm 0.08$ & 0.8 & 6.8 & 0.6 & 2.9 \\
\hline & & 5.82 & $5.77 \pm 0.02$ & 0.3 & 3.6 & -0.9 & 2.4 \\
\hline & & 2.33 & $2.26 \pm 0.01$ & 0.7 & 6.1 & -3.2 & 8.3 \\
\hline & \multirow[t]{3}{*}{ SWM } & 5.38 & $5.02 \pm 0.36$ & 7.3 & 3.0 & -6.6 & -0.6 \\
\hline & & 3.82 & $3.38 \pm 0.07$ & 2.1 & 4.9 & -11.4 & -1.8 \\
\hline & & 2.26 & $2.00 \pm 0.09$ & 4.7 & 7.7 & -11.2 & -0.6 \\
\hline & \multirow[t]{3}{*}{ SWS } & 3.84 & $4.06 \pm 0.21$ & 2.0 & 3.6 & 5.8 & -0.3 \\
\hline & & 2.98 & $2.50 \pm 0.09$ & 12.3 & 13.6 & -4.5 & -2.3 \\
\hline & & 2.11 & $1.92 \pm 0.03$ & 1.4 & 9.1 & -9.1 & -3.5 \\
\hline
\end{tabular}

can be obtained and the extraction recovery were range from $74.1 \pm 1.1$ to $107.4 \pm 3.7 \%$. The corresponding results of intra-day and inter-day accuracy and precision were listed in Table 4. Apparently, both Intra- and interday relative standard deviation of the concentrations of four analytes in urine and feces QC samples for middle and high concentrations were within $\pm 10 \%$, for low concentrations were in the range of $\pm 20 \%$. Thus, this method is accurate and precise for the direct determination of four bioactive ingredients in urine and feces samples.

Moreover, the stability of the analytes in rat urine and feces QC samples were determined. Four different sample preprocessing methods, including short term, long term, freeze-thaw, and post-preparation, were employed. Shortterm and long-term stability were evaluated by storing the frozen samples at room temperature for $8 \mathrm{~h}$ and at $-80^{\circ} \mathrm{C}$ in a freezer for 21 days. Freeze-thaw stability was assessed after three cycles; then, QC samples were frozen at $-80{ }^{\circ} \mathrm{C}$ for $12 \mathrm{~h}$ and thawed. Post-preparation was evaluated after the processed samples were stored in an autosampler tray for $24 \mathrm{~h}$. The high, middle, and low concentration levels of QC samples were predicted in triplicate with the aid of ATLD and then compared with actual concentrations. All the relative deviations were within $\pm 15 \%$. The stability of QC samples was acceptable under indicated storage conditions, as shown in Table 5. Hence, this method provides satisfactory stability for determining the four analytes and offer considerable potential to be tailored as a routine method for analyzing the excretion of TCM.

\subsection{Study on Kinetics of Excretion}

\subsubsection{Simultaneous Determination of Four Bioactive Ingredients in Rat Excrement}

The established method based on second-order calibration strategy was applied to analyze urine and feces samples after the oral administration of Radix Gentianae Macrophyllae water decoctions. After the appropriate component numbers were estimated using core consistency diagnostic (CORCONDIA) [48], three-way data arrays obtained from 
Table 5 Stability of four analytes in urine and feces samples based on ATLD algorithm

\begin{tabular}{|c|c|c|c|c|c|c|c|c|c|c|}
\hline \multirow[t]{2}{*}{ Matrix } & \multirow[t]{2}{*}{ Analytes } & \multirow{2}{*}{$\begin{array}{l}\text { Concentration } \\
\text { Spiked } \\
\left(\mu \mathrm{g} \mathrm{mL}^{-1}\right)\end{array}$} & \multicolumn{2}{|c|}{$\begin{array}{l}\text { Room-temperature for } \\
8 \mathrm{~h}\end{array}$} & \multicolumn{2}{|c|}{$\begin{array}{l}\text { In the auto-sampler for } \\
24 \mathrm{~h}\end{array}$} & \multicolumn{2}{|c|}{$\begin{array}{l}\text { Three freeze cycles in rat } \\
\text { urine }\end{array}$} & \multicolumn{2}{|c|}{$\begin{array}{l}\text { Long-term stability } \\
\left(-80^{\circ} \mathrm{C}, 21 \text { days }\right)\end{array}$} \\
\hline & & & $\begin{array}{l}\text { Measured } \\
(\text { mean } \pm \mathrm{SD})\end{array}$ & $\begin{array}{l}\mathrm{RE} \\
(\%)\end{array}$ & $\begin{array}{l}\text { Measured } \\
(\text { mean } \pm \mathrm{SD})\end{array}$ & $\begin{array}{l}\mathrm{RE} \\
(\%)\end{array}$ & $\begin{array}{l}\text { Measured } \\
(\text { mean } \pm \mathrm{SD})\end{array}$ & $\begin{array}{l}\mathrm{RE} \\
(\%)\end{array}$ & $\begin{array}{l}\text { Measured } \\
(\text { mean } \pm \mathrm{SD})\end{array}$ & $\begin{array}{l}\mathrm{RE} \\
(\%)\end{array}$ \\
\hline \multirow[t]{13}{*}{ Urine } & \multirow[t]{3}{*}{ GPS } & 8.32 & $7.46 \pm 0.18$ & -10.2 & $8.39 \pm 0.17$ & 1.0 & $9.17 \pm 0.78$ & 10.4 & $7.79 \pm 0.34$ & -6.2 \\
\hline & & 5.10 & $4.99 \pm 0.16$ & -2.1 & $4.64 \pm 0.06$ & -8.7 & $5.03 \pm 0.09$ & -1.2 & $4.83 \pm 0.12$ & -5.1 \\
\hline & & 1.87 & $1.36 \pm 0.16$ & -14.9 & $1.91 \pm 0.06$ & 2.1 & $2.01 \pm 0.36$ & 7.8 & $1.94 \pm 0.13$ & 3.7 \\
\hline & \multirow[t]{3}{*}{ LOG } & 9.71 & $9.91 \pm 0.05$ & 2.2 & $10.23 \pm 0.05$ & 5.6 & $9.27 \pm 0.07$ & -4.3 & $8.36 \pm 0.16$ & -13.8 \\
\hline & & 6.07 & $6.71 \pm 0.04$ & 10.8 & $6.27 \pm 0.04$ & 3.6 & $5.85 \pm 0.11$ & -3.4 & $6.13 \pm 0.17$ & 1.3 \\
\hline & & 2.43 & $2.41 \pm 0.09$ & -0.5 & $2.79 \pm 0.05$ & 15.0 & $2.75 \pm 0.10$ & 13.5 & $2.08 \pm 0.05$ & -14.2 \\
\hline & \multirow[t]{3}{*}{ SWM } & 5.60 & $5.53 \pm 0.35$ & -1.1 & $5.30 \pm 0.01$ & -5.3 & $5.17 \pm 0.08$ & -7.6 & $5.18 \pm 0.91$ & -7.5 \\
\hline & & 3.98 & $4.13 \pm 0.27$ & 3.9 & $4.46 \pm 0.07$ & 12.4 & $4.25 \pm 0.05$ & 7.1 & $4.47 \pm 0.18$ & 12.6 \\
\hline & & 2.35 & $2.40 \pm 0.13$ & 2.1 & $2.34 \pm 0.12$ & -0.2 & $2.41 \pm 0.02$ & 2.4 & $2.33 \pm 0.34$ & -0.7 \\
\hline & \multirow[t]{3}{*}{ SWS } & 4.00 & $4.04 \pm 0.57$ & 1.1 & $3.91 \pm 0.18$ & -2.2 & $4.10 \pm 0.66$ & 2.8 & $3.87 \pm 0.88$ & -3.1 \\
\hline & & 3.10 & $3.49 \pm 0.36$ & 13.4 & $3.28 \pm 0.28$ & 5.9 & $2.89 \pm 0.15$ & -6.8 & $3.18 \pm 0.36$ & 2.8 \\
\hline & & 2.20 & $2.49 \pm 0.07$ & 2.1 & $2.50 \pm 0.07$ & 13.5 & $1.97 \pm 0.08$ & -10.3 & $2.01 \pm 0.02$ & -8.6 \\
\hline & \multirow[t]{3}{*}{ GPS } & 7.99 & $8.66 \pm 0.31$ & 8.5 & $8.63 \pm 0.10$ & 8.1 & $7.11 \pm 0.67$ & -11.0 & $7.26 \pm 0.79$ & -9.1 \\
\hline \multirow[t]{11}{*}{ Feces } & & 4.89 & $4.80 \pm 0.14$ & -2.0 & $4.96 \pm 0.05$ & 1.4 & $4.18 \pm 0.30$ & -14.6 & $4.76 \pm 0.06$ & 11.0 \\
\hline & & 1.80 & $1.66 \pm 0.06$ & -7.4 & $2.10 \pm 0.03$ & 16.7 & $1.69 \pm 0.32$ & -5.6 & $1.72 \pm 0.29$ & -4.4 \\
\hline & \multirow[t]{3}{*}{ LOG } & 9.32 & $9.73 \pm 0.04$ & 4.5 & $9.63 \pm 0.13$ & 3.4 & $8.55 \pm 0.69$ & -8.3 & $10.01 \pm 0.16$ & 7.4 \\
\hline & & 5.82 & $6.40 \pm 0.10$ & 9.8 & $6.43 \pm 0.19$ & -3.9 & $5.54 \pm 0.14$ & -4.9 & $6.18 \pm 0.17$ & 6.2 \\
\hline & & 2.33 & $2.92 \pm 0.61$ & -5.0 & $2.44 \pm 0.04$ & 4.7 & $2.20 \pm 0.03$ & -5.5 & $2.15 \pm 0.02$ & -7.9 \\
\hline & \multirow[t]{3}{*}{ SWM } & 5.38 & $6.16 \pm 0.45$ & 14.6 & $5.55 \pm 0.48$ & 3.2 & $5.32 \pm 0.47$ & -1.0 & $4.99 \pm 0.57$ & -7.1 \\
\hline & & 3.82 & $3.86 \pm 0.36$ & 1.2 & $3.71 \pm 0.23$ & -2.8 & $4.12 \pm 0.32$ & 8.0 & $3.40 \pm 0.21$ & -11.0 \\
\hline & & 2.26 & $2.19 \pm 0.04$ & -3.0 & $2.44 \pm 0.16$ & 8.1 & $2.46 \pm 0.01$ & 9.0 & $2.59 \pm 0.18$ & 14.6 \\
\hline & \multirow[t]{3}{*}{ SWS } & 3.84 & $4.36 \pm 0.27$ & 13.5 & $4.01 \pm 0.05$ & 4.4 & $3.95 \pm 0.38$ & 2.9 & $3.64 \pm 0.06$ & -5.2 \\
\hline & & 2.98 & $3.11 \pm 0.09$ & 4.6 & $3.05 \pm 0.02$ & 2.6 & $3.00 \pm 0.19$ & 0.8 & $2.92 \pm 0.18$ & 0.8 \\
\hline & & 2.11 & $2.26 \pm 0.02$ & 6.8 & $2.30 \pm 0.03$ & 9.1 & $2.39 \pm 0.27$ & 13.0 & $2.14 \pm 0.15$ & 1.1 \\
\hline
\end{tabular}

HPLC-DAD analysis for calibration and prediction samples were decomposed using ATLD. The actual spectral and elution time profiles together with their corresponding loadings were obtained from the decomposition of the HPLC-DAD data array by ATLD. Resolution results for rat urine and feces samples administered with Radix Gentianae Macrophyllae water decoction at a low concentration level are shown in Fig. 3. Loadings in the wavelength and elution time modes of SWM and SWS were almost similar to the actual values, implying the reliability and stability of the new analytical strategy. The slight deviation between the actual and fitting chromatographic profiles of LOG, GPS, and consistency degree (CD) values was compared to assess the consistency of the resolution and actual chromatographic profiles. The formula of $\mathrm{CD}$ is expressed as: $\mathrm{CD}=\min \left(\cos \left(a_{\mathrm{a}}, a_{\mathrm{r}}\right), \cos \left(b_{\mathrm{a}}, b_{\mathrm{r}}\right)\right)$, where cos means cosine, $a_{\mathrm{a}}$ and $b_{\mathrm{a}}$ are the actual chromatographic and spectral profiles of the target analyte, respectively, and $a_{\mathrm{r}}$ and $b_{\mathrm{r}}$ are the resolved chromatographic and spectral profiles, respectively. The $\mathrm{CD}$ values are close to 1 , indicating highly effective mathematical separation of bioactive ingredient information in biological excretion samples. The CDs of GPS and LOG in chromatographic profiles for urine samples were calculated as 0.8111 and 0.8053 , respectively, and CDs of GPS and LOG in spectral profiles for urine samples were 0.9831 and 0.9824 , respectively. The requirement of quantitative analysis was fulfilled, and satisfactory results could be obtained for feces samples by using a similar calculation method. These results are acceptable in practical applications and further confirm that the proposed method accurately quantifies the analytes of interest even in different complex matrices.

The resolved relative concentration contributions for each analyte of interest were independently regressed against the corresponding standard concentrations from calibration samples. Thus, we can predict the 

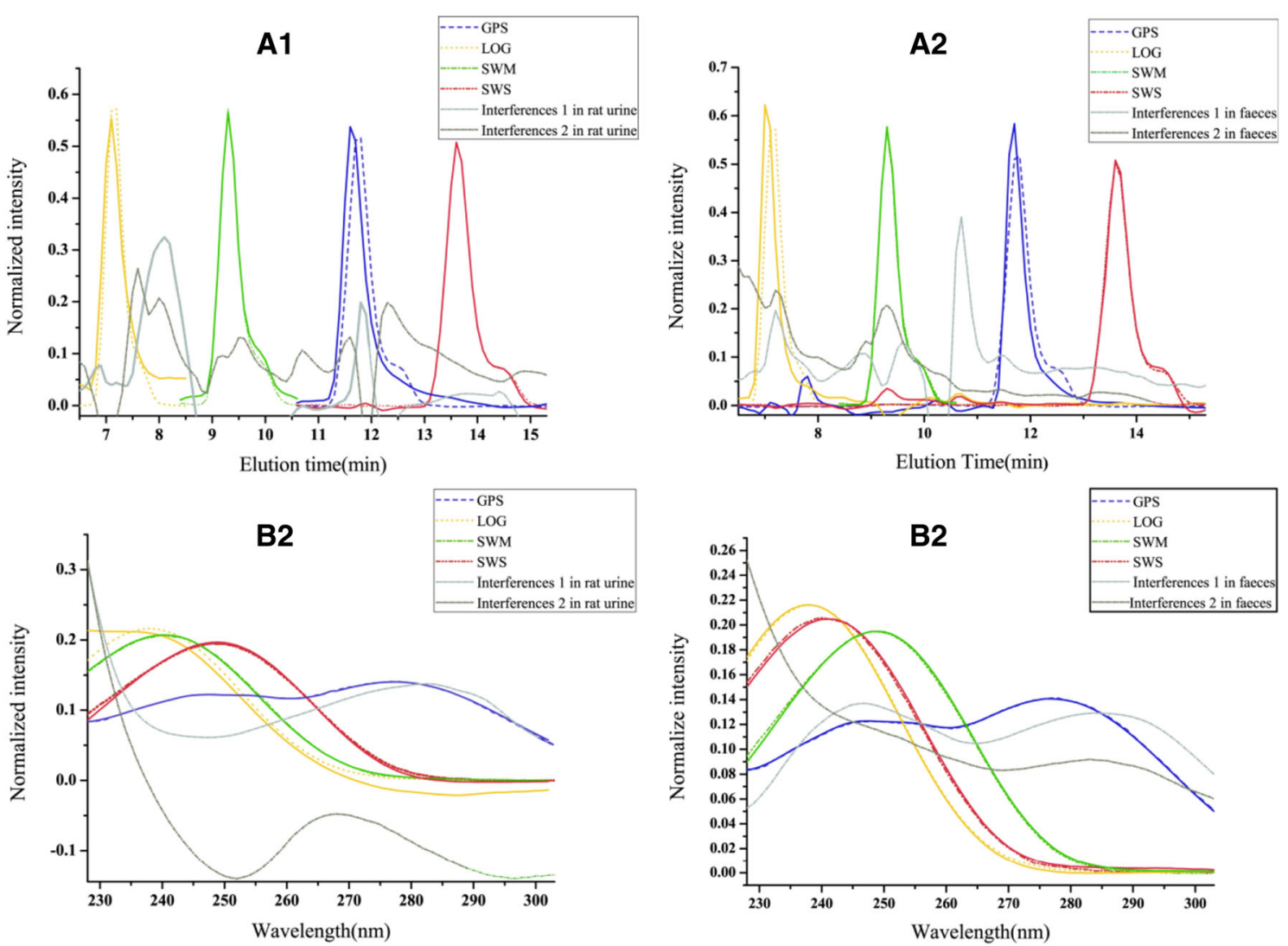

Fig. 3 Actual and resolved elution profiles (a1) and wavelength profiles (b1) of four bioactive ingredients in rat urine by using ATLD. Actual and resolved elution profiles (a2) and wavelength profiles (b2) of four bioactive ingredients in rat feces by using ATLD. Solid lines,

concentrations of the four active ingredients in the excrement of rats orally administered with low, middle, and high dosages at different time points. The synergistic relationships and cumulative excretion of the four bioactive components of Radix Gentianae Macrophyllae are shown in Fig. 4. The maximum excretion for GPS, LOG, and SWS was recorded in the time range of 4-8 $\mathrm{h}$, whereas the corresponding data for SWM were recorded within 0-2 h. In urine samples, the cumulative excretion values of GPS, LOG, SWM, and SWS within 0-48 h were only $7.5,4.7$, 6.3 , and $9.4 \%$ of the initial dosage, respectively; hence, these components are limitedly excreted in their initial forms. In feces samples, the cumulative excretion values of GPS, LOG, SWM, and SWS within 0-48 h were 0.9, 10.6, 35.4 , and $12.0 \%$ of the initial dosage, respectively, with SWM exhibiting higher fecal excretion compared with other bioactive components.

According to the available literature on the pharmacokinetics of GPS, SWM, and SWS, the three components show low oral bioavailability of $39.6,10.0$, and $0.31 \%$, respectively. The four active components of Radix Gentianae Macrophyllae may be converted into other dotted solid lines, and dotted lines represent the actual spectral profiles of four analytes, the loadings for four analytes, and inherent interference from rat urine or feces, respectively

components via biotransformation, and GPS reportedly transform into five active constituents [49]. In addition, SWS exhibits high biliary excretion rate of approximately $31.2 \%$ with low bioavailability in vivo. This low availability may be due to the high polarity of SWS, which makes direct absorption difficult. Otherwise, SWS is metabolized by intestinal bacteria by first-pass effect. GPS, SWM, and SWS are mainly excreted by the kidneys and in bile and feces. Based on these considerations, the present study on the pharmacokinetics of Radix Gentianae Macrophyllae is of considerable significance in pharmacokinetic research.

\subsubsection{Figures of Merit}

FOMs, including SEL, SEN, LOD, and LOQ, should be calculated to validate the second-order calibration method. FOMs in the matrix of rat urine and feces samples are listed in Table 6. Results show that the new method can provide satisfactory predictive results in the quantitative analysis of four analytes in rat excrement, overcome the influences of unknown interferences from complicated biological matrix, 

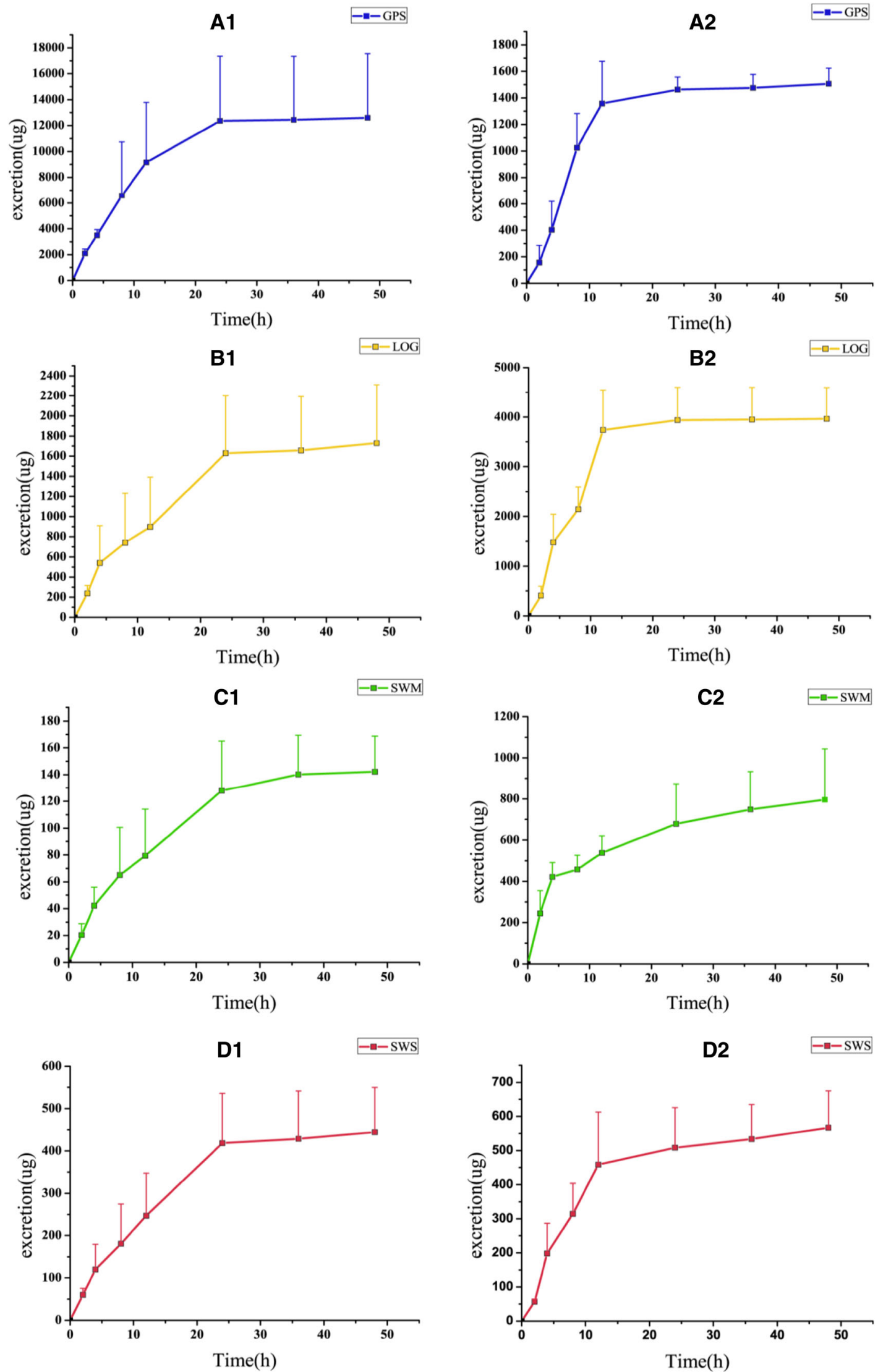
4Fig. 4 The cumulative excretion(mean + SD) of four bioactive ingredients in urine (a1, b1, c1, d1) and in feces $(\mathbf{a} 2, \mathbf{b 2}, \mathbf{c 2}, \mathbf{d 2})$, respectively

and avoid tedious pretreatments, such as solid-phase extraction. Therefore, experimental efficiency and accuracy can be markedly improved.

\subsection{Verification of HPLC-MS Results}

For verifying the accuracy of the simultaneous determination of four analytes, urine samples collected from 2 to 4 and 4 to $8 \mathrm{~h}$ after the oral administration of a $16 \mathrm{~g} \mathrm{~kg}^{-1}$ Radix Gentianae Macrophyllae water decoction were selected as a typical example because of their complex background matrix, which severely overlapped with target analytes. Student's $t$-test was applied to compare the significant difference of concentrations based on ATLD and HPLC-MS. The simultaneous determination of the four bioactive ingredients in urine samples by ATLD and LCMS is compared in Table 7. The RE values of four bioactive components was less than $16 \%$, and the predicted concentrations by ATLD and the concentrations provided

Table 6 FOM of four analytes in urine and feces samples using ATLD algorithm

\begin{tabular}{|c|c|c|c|c|c|c|c|c|c|}
\hline & \multirow[t]{2}{*}{$\mathrm{n}$} & \multicolumn{4}{|l|}{ Urine samples } & \multicolumn{4}{|l|}{ Feces samples } \\
\hline & & $\operatorname{LOD}\left(\mu \mathrm{g} \mathrm{mL}^{-1}\right)$ & $\mathrm{LOQ}\left(\mu \mathrm{g} \mathrm{mL} \mathrm{L}^{-1}\right)$ & $\operatorname{SEN}\left(\mathrm{mL} \mu \mathrm{g}^{-1}\right)$ & SEL & $\operatorname{LOD}\left(\mu \mathrm{g} \mathrm{mL}^{-1}\right)$ & $\mathrm{LOQ}\left(\mu \mathrm{g} \mathrm{mL}{ }^{-1}\right)$ & $\operatorname{SEN}\left(\mathrm{mL} \mu \mathrm{g}^{-1)}\right.$ & SEL \\
\hline \multirow[t]{5}{*}{ GPS } & 1 & 0.02 & 0.05 & 2.45 & 0.67 & 0.06 & 0.18 & 1.93 & 0.56 \\
\hline & 2 & 0.59 & 1.80 & 3.24 & 0.57 & 0.30 & 0.90 & 0.81 & 0.22 \\
\hline & 3 & 0.59 & 1.80 & 2.23 & 0.47 & 0.06 & 0.18 & 1.93 & 0.55 \\
\hline & 4 & 0.06 & 0.18 & 1.44 & 0.47 & 0.06 & 0.18 & 1.79 & 0.58 \\
\hline & 5 & 0.06 & 0.18 & 1.49 & 0.49 & 0.06 & 0.18 & 1.28 & 0.38 \\
\hline \multirow[t]{5}{*}{ LOG } & 1 & 0.43 & 1.30 & 2.63 & 0.62 & 0.48 & 1.44 & 1.09 & 0.29 \\
\hline & 2 & 0.16 & 0.48 & 2.01 & 0.47 & 0.16 & 0.48 & 0.78 & 0.21 \\
\hline & 3 & 0.42 & 1.27 & 1.35 & 0.35 & 0.08 & 0.24 & 1.81 & 0.52 \\
\hline & 4 & 0.02 & 0.07 & 2.34 & 0.57 & 0.87 & 2.64 & 1.05 & 0.28 \\
\hline & 5 & 0.32 & 0.96 & 1.01 & 0.39 & 0.08 & 0.24 & 0.98 & 0.27 \\
\hline \multirow[t]{5}{*}{ SWM } & 1 & 0.07 & 0.21 & 0.18 & 1.55 & 0.70 & 2.11 & 0.91 & 0.46 \\
\hline & 2 & 0.38 & 1.16 & 0.57 & 0.58 & 0.97 & 2.95 & 0.93 & 0.42 \\
\hline & 3 & 0.40 & 1.22 & 0.13 & 0.34 & 0.15 & 0.45 & 0.68 & 0.37 \\
\hline & 4 & 0.26 & 0.78 & 0.62 & 0.42 & 0.17 & 0.52 & 0.69 & 1.00 \\
\hline & 5 & 0.15 & 0.47 & 0.40 & 0.39 & 0.64 & 1.94 & 0.73 & 0.43 \\
\hline \multirow[t]{5}{*}{ SWS } & 1 & 0.13 & 0.39 & 1.03 & 0.26 & 0.04 & 0.11 & 0.86 & 0.25 \\
\hline & 2 & 0.08 & 0.24 & 1.32 & 0.51 & 0.36 & 1.09 & 0.84 & 0.28 \\
\hline & 3 & 0.30 & 0.90 & 1.66 & 0.57 & 0.23 & 0.69 & 0.78 & 0.26 \\
\hline & 4 & 0.28 & 0.86 & 1.53 & 0.50 & 0.00 & 0.01 & 0.87 & 0.25 \\
\hline & 5 & 0.27 & 0.82 & 1.86 & 0.64 & 0.09 & 0.26 & 0.81 & 0.23 \\
\hline
\end{tabular}

Table 7 The comparison of simultaneous determination of four bioactive ingredients in urine samples by the algorithm of ATLD and LC-MS

\begin{tabular}{|c|c|c|c|c|c|c|}
\hline \multirow[t]{2}{*}{ Ingredients } & \multicolumn{3}{|l|}{$t(2-4 h)$} & \multicolumn{3}{|l|}{$\mathrm{t}(4-8 \mathrm{~h})$} \\
\hline & $\operatorname{ATLD}\left(\mu \mathrm{g} \mathrm{mL}^{-1}\right)$ & LC-MS $\left(\mu \mathrm{g} \mathrm{mL}^{-1}\right)$ & $\mathrm{RE}(\%)$ & $\operatorname{ATLD}\left(\mu \mathrm{g} \mathrm{mL}^{-1}\right)$ & LC-MS $\left(\mu \mathrm{g} \mathrm{mL}^{-1}\right)$ & $\operatorname{RE}(\%)$ \\
\hline GPS & 84.56 & 84.88 & -0.4 & 97.36 & 96.95 & 0.4 \\
\hline LOG & 0.77 & 0.77 & 0.0 & 1.34 & 1.58 & -15.2 \\
\hline SWM & 11.07 & 11.99 & -7.7 & 22.97 & 23.39 & -1.8 \\
\hline SWS & 2.14 & 1.85 & 15.7 & 3.50 & 3.28 & 6.7 \\
\hline T-test & \multicolumn{3}{|l|}{$0.37<t_{0.025}^{3}$} & \multicolumn{3}{|l|}{$0.52<t_{0.025}^{3}$} \\
\hline
\end{tabular}


by HPLC-MS were not significantly different at $95 \%$ confidence level This result indicates that ATLD can directly determine the concentration of four bioactive ingredients in complex urine and feces samples.

\section{Conclusion}

In this paper, a novel and effective multi-dimensional quantitative characterization model was successfully established to investigate the synergistic excretion and conduct pharmacokinetic analysis of four bioactive ingredients in Radix Gentianae Macrophyllae by using HPLCDAD and ATLD with aid of region selection. The total cumulative excretion of GPS, LOG, SWM, and SWS in urine and feces samples collected within different excretive time intervals after oral administration of the water decoction was calculated to reveal the synergistic relationships. The accuracy of the proposed method was validated using HPLC-MS. FOMs, including SEN, SEL, LOD, and LOQ, were evaluated. All results indicated that the proposed method can not only provide a convenient, rapid, and reliable reference method for the analysis of complex excretion samples but also show marked potential for further tailoring as a general and promising approach to study the pharmacokinetics of TCM and natural products.

Acknowledgements Authors are grateful to the financial support from the National Natural Science Foundation of China (Grants Nos. 21776321, 21576297, 21205145, 21575039) and Key Projects of Technological Innovation of Hubei Province (2016ACA138). The Open Research Program (Grant Nos. 2015ZD001, 2015ZD002 and 2015ZY006) from the Modernization Engineering Technology Research Center of Ethnic Minority Medicine of Hubei province (South-Central University for Nationalities).

\section{Compliance with Ethical Standards}

Conflict of interest All authors declare no conflict of interest.

Open Access This article is distributed under the terms of the Creative Commons Attribution 4.0 International License (http://creative commons.org/licenses/by/4.0/), which permits unrestricted use, distribution, and reproduction in any medium, provided you give appropriate credit to the original author(s) and the source, provide a link to the Creative Commons license, and indicate if changes were made.

\section{References}

1. Y. Wang, B. Ahmad, B. Duan, Z. Rui, L. Huang, Chem. Biodivers. 13, 776-781 (2016)

2. N. Jia, Y. Li, Y. Wu, M. Xi, G. Hur, X. Zhang, J. Cui, W. Sun, A. Wen, J. Ethnopharmacol. 144, 638-645 (2012)

3. X.Y. Cao, Z.Z. Wang, Phytochem. Anal. 21, 348 (2010)

4. A.Z. Nie, Z.J. Lin, Y. Wang, B. Zhang, Chin. Tradit. Herbal Drugs 48, 597-608 (2017)
5. W.L. Changliao, C.F. Chien, L.C. Lin, T.H. Tsai, J. Ethnopharmacol. 141, 668-673 (2012)

6. T.M. Ma, F. Liu, R. Wang, H.Q. Gao, Chin. Tradit. Herbal Drugs 48, 1812-1819 (2017)

7. Y. Liu, J.M. Kong, L.S. Chia, N.K. Goh, Asian J. Chem. 19, 867-882 (2007)

8. W.J. Kong, Y.L. Zhao, X.H. Xiao, C. Jin, Z.L. Li, Phytomedicine 16, 950 (2009)

9. Z. Rao, F. Zhang, X.Y. Zhang, G.Q. Zhang, Y.R. Ma, Y. Zhou, H.Y. Qin, X.A. Wu, Y.H. Wei, Biomed. Chromatogr. 29, 1453 (2015)

10. Y.Y. Cheng, T.H. Tsai, Molecules 21, 1159 (2016)

11. M.K. Choi, J. Lee, S.J. Nam, Y.J. Kang, Y. Han, K. Choi, Y.A. Choi, M. Kwon, D. Lee, I.S. Song, Mar. Drugs 15, 279 (2017)

12. T.C.D. Figueiredo, D.C.S.D. Assis, L.D.M. Menezes, G.R.D. Silva, I.P. Lanza, L.G.D. Heneinec, S.D.V. Cancadoa, Talanta 142, 240-245 (2015)

13. N. Moghbel, B.M. Ryu, K.J. Steadman, J. Chromatogr. B 997, $142(2015)$

14. Y. Shao, W. Zhang, L. Tong, J. Huang, D. Li, W. Nie, Y. Zhu, Y. Li, T. Lu, Biomed. Chromatogr. 31, e3941 (2017)

15. L. Zheng, Z. Gong, Y. Lu, Y. Xie, Y. Huang, Y. Liu, Y.Y. Lan, A.M. Wang, Y.L. Wang, J. Chromatogr. B 997, 210-217 (2015)

16. M. Shariati-Rad, M. Irandoust, F. Niazi, J. Anal. Chem. 71, 660-666 (2016)

17. J. Aimo, E. Promancio, P.C. Damiani, Anal. Methods 8, 4617-4631 (2016)

18. X.H. Zhang, H.L. Wu, J.Y. Wang, D.Z. Tu, C. Kang, J. Zhao, Y Chen, X.X. Miu, R.Q. Yu, Food Chem. 138, 62-69 (2013)

19. Y.J. Yu, H.L. Wu, S.Z. Shao, C. Kang, J. Zhao, Y. Wang, S.H. Zhu, R.Q. Yu, Talanta 85, 1549-1559 (2011)

20. H. Ayvaz, L.E. Rodriguez-Saona, Food Chem. 174, 154 (2015)

21. Y.M. Sun, W.U. Hai-Long, J.Y. Wang, Y.U. Ru-Qin, Chem. J. Chin. Univ. 34, 1084-1091 (2013)

22. C.L. Boucher, F. Courant, A.L. Royer, S. Jeanson, S. Lortal, G. Dervilly-Pinel, A. Thierry, B.L. Bizec, Metabolomics 11 1117-1130 (2015)

23. X.L. Yin, H.L. Wu, H.W. Gu, X.H. Zhang, Y.M. Sun, Y. Hu, L. Liu, Q.M. Rong, R.Q. Yu, J. Chromatogr. A 1364, 151-162 (2014)

24. A.V. Schenone, M.J. Culzoni, N.R. Marsili, H.C. Goicoechea, Food Chem. 138, 1928-1935 (2013)

25. D.Z. Tu, H.L. Wu, Y.N. Li, J. Zhang, Y. Li, C.C. Nie, X.H. Zhang, R.Q. Yu, Anal. Methods 4, 222-229 (2012)

26. J.Y. Wang, H.L. Wu, Y. Chen, M. Zhai, X.D. Qing, R.Q. Yu, Talanta 116, 347-353 (2013)

27. X.D. Qing, H.L. Wu, Y.N. Li, C.C. Nie, J.Y. Wang, S.H. Zhu, R.Q. Yu, Anal. Methods 4, 685 (2012)

28. E. Fuentes, C. Cid, M.E. Báez, Talanta 134, 8-15 (2015)

29. R. Yang, N. Zhao, X. Xiao, G. Yin, S. Y, J. Liu, W. Liu, Opt. Express 24, A1148 (2016)

30. M. Vosough, E.H. Mashhadiabbas, Talanta 113, 68 (2013)

31. A.P. Pagani, G.A. Ibañez, Talanta 122, 1 (2014)

32. W.P. Sheffield, V. Bhakta, Biochem. Biophys. Res. Commun. 470, 710 (2016)

33. E.C.Y. Yan, Z. Wang, L. Fu, Phys. Chem. B 119, 2769-2785 (2015)

34. M. Vosough, S.N. Eshlaghi, R. Zadmard, Spectrochim. Acta 136, 618-624 (2015)

35. S.S. Li, H.L. Wu, Y.J. Liu, H.W. Gu, R.Q. Yu, Chin. Chem. Lett. 24, 239-242 (2013)

36. A.P. Pagani, G.A. Ibanez, Talanta 122, 1-7 (2014)

37. Y.M. Sun, H.L. Wu, J.Y. Wang, Z. Liu, M. Zhai, R.Q. Yu, J. Chromatogr. B 962, 59-67 (2014)

38. M. Kooshki, H. Abdollahi, S. Bozorgzadeh, B. Haghighi, Electrochim. Acta 56, 8618-8624 (2011) 
39. G.N. Piccirilli, G.M. Escandar, Analyst 135, 1299 (2010)

40. A.V. Schenone, M.J. Culzoni, M.M. Galera, H.C. Goicoechea, Talanta 109, 107-115 (2013)

41. J. Gu, H. Li, K. Pei, H. Cai, K. Qin, X. Zhang, L. Zheng, X. Liu, Y. Cai, B. Cai, J. Chromatogr. B 973C, 120-125 (2014)

42. M.Y. He, Y.X. Deng, Q.Z. Shi, X.J. Zhang, Y. Lv, J. Ethnopharmacol. 155, 334-342 (2014)

43. J. Yuan, Y. Wang, R. An, S. Wang, S.J. Li, J.Y. Jia, S.W.A. Bligh, X.H. Wang, Y.M. Ma, J. Chromatogr. B 895-896, 154-161 (2012)
44. S. Zhan, Q. Shao, X. Fan, Z. Li, Biomed. Chromatogr. 29, 275-284 (2015)

45. J.A. Arancibia, P.C. Damiani, G.M. Escandar, G.A. Ibanez, A.C. Olivieri, J. Chromatogr. B 910, 22-30 (2012)

46. G.M. Escandar, H.C. Goicoechea, A. Munoz de la Pena, A.C. Olivieri, Anal. Chim. Acta 806, 8-26 (2014)

47. H.L. Wu, M. Shibukawa, K. Oguma, J. Chemom. 12, 1-26 (1998)

48. M.H. Kamstrup-Nielsen, L.G. Johnsen, R. Bro, J. Chemom. 27, 99-105 (2013)

49. Z.G. Wang, S.S. Wang, Y.J. Sun, H.Y. Wang, G. Chen, X.J. Wang, M. Hattori, H.L. Zhang, J. Sep. Sci. 37, 237-243 (2014) 